\title{
Cross Inoculation and Host Range Studies of Rhizoctonia solani Kuhn Infecting Small Millets
}

\author{
Varala Krishnaveni*, Savita Ekka, H. C. Lal and N. Kudada
}

Department of Plant Pathology, Ranchi Agriculture College, BAU, Ranchi, Jharkhand, India

*Corresponding author

\section{A B S T R A C T}

\begin{tabular}{|l|}
\hline K e y w o r d s \\
Banded sheath \\
blight, Rhizoctonia \\
solani, \\
$\begin{array}{l}\text { Pathogenicity, Host } \\
\text { range, Cross } \\
\text { inoculation }\end{array}$ \\
\hline Article Info \\
\hline $\begin{array}{l}\text { Accepted: } \\
\text { 12 October } 2020 \\
\text { Available Online: } \\
\text { 10 November } 2020\end{array}$ \\
\hline
\end{tabular}

\section{Introduction}

Rhizoctonia solani Kuhn (Teleomorph: Thanatephorus cucumeris) is a soil born, necrotrophic plant pathogenic fungus with a wide host range. It is a polyphagous fungus attack large number of plant species around the world with diverse symptoms (Ploetz et $a l .$, 1985). It causes sheath blight disease on a wide range of Graminae plant hosts.The pathogen is genetically diverse showing variability in respect of cultural/ morphological and physiological characters.It is a complex pathogen with great variation in terms of mycelial colour, zonation, dispersion, number of sclerotia, size of sclerotia, growth rate, saprophytic behaviour, enzyme production and pathogenicity (Hyakumachi et al., 1988). In recent years, it is an emerging problem in small millets causing banded sheath blight disease. Under field conditions, symptoms were similar in all small millets, primarily symptoms were appeared as small $2-3 \mathrm{~cm}$ long, oval to irregular and light grey to dark brown lesions on the leaf sheath. The central portions lesions later turned greyish white to straw coloured with narrow, reddish-brown margins, which appeared as series of copper and brown coloured bands across the leaf 
sheaths giving a very characteristic banded appearance. Similar symptoms were observed by Dubey (1995) in finger millet and Patro et al., (2018) in proso millet. In later stages, lesions were associated with white mycelial fungal growth and sclerotia. Shailbala and Tripathi (2007) also stated that on the symptom of web blight of urd bean white mycelial fungal growth and sclerotia were present in the lesions at the later stages of infection.

Due to its diversity and wide host range, it is hugely problematic in successful cultivation of small millets. Keeping in view, present investigation is carried out to on Cross inoculation and Host range studies of $R$. solani infecting small millets.

\section{Materials and Methods}

\section{Collection, isolation and purification of pathogen}

Fifty three samples of Rhizoctonia solani Kuhn were collected from Finger millet, foxtail millet, proso millet and little millet showing typical banded sheath blight at Research farm of Birsa Agricultural University, Kanke, Ranchi, Jharkhand during Kharif, 2018. These isolates were purified, identified and maintained in the laboratory.

\section{Pathogenicity test}

All the isolates collected were tested for their pathogenicity under glasshouse conditions by adopting two different inoculation methods viz., Sheath inoculum method and Agar method. For the experimentation, susceptible variety of foxtail millet (SiA3282), finger millet (Udrumellege), Proso millet (CO 5) and Little millet (OLM 95) seedlings were sown in $30 \mathrm{~cm}$ surface sterilized earthen pots containing sterilized soil.

\section{Agar method}

Pathogenicity test through Agar method were performed on 30 days old healthy plants by placing the mycelial discs cut from four days old cultures of the each isolate on the surface of three healthy leaves of the respective crops.

\section{Sheath inoculam method}

In sheath inoculum method, leaves of all four small millets were collected, cut into small pieces $(4 \mathrm{~cm})$, placed in conical flask, added desired quantity of water and closed with a cotton plug. The flasks were autoclaved at a pressure of $1.1 \mathrm{~kg}$ per $\mathrm{cm}^{2}\left(121^{0} \mathrm{C}\right)$ for twenty minutes, inoculated with the test pathogen and incubated at room temperature at $27 \pm 1^{0} \mathrm{C}$ for 10 days.

The mycelium grew extensively and sclerotia developed profusely on these leaves within 10 days. These leaf bits having mycelium and sclerotia were used as inoculum placed in the center of the tillers in pots. The un-inoculated seedlings were kept as control maintaining three replications. Wherever isolates produced typical banded sheath blight symptoms, the fungus was successfully re-isolated and Koch's postulates have proved.

\section{Cross inoculation studies}

The cross-infectivity of pathogen was studied by detached leaf inoculation method (Dath, 1985). In this technique, each leaflet $(7 \mathrm{~cm}$ long) were placed over moist filter paper in petri Figs and artificially inoculated with a 5 mm diameter mycelia disc from 7 days old $R$. solani culture.

Another leaves were kept healthy without inoculation and maintained as control. On five to seven days after inoculation the leaves were regularly examined for appearance of symptoms. 


\section{Host range studies}

In order to find out the host range of $R$. solani (fast, medium and slow growing isolates), 5 plant species belonging to families Graminae (rice, sorghum \& bajra) and Leguminaceae (groundnut \& soybean) were raised in $30 \mathrm{~cm}$ diameter pots filled with sterilized soil during Kharif, 2018 at the Department of Plant Pathology, Kanke, Ranchi.

The test pathogens were inoculated by placing the sclerotia in the root zone of the plant species belonging to family Leguminaceae. For the plant species belonging to family Graminae the sclerotia were placed by opening the sheath region, covering with moist cotton and sprinkled with a few drops of sterile distilled water regularly for $24 \mathrm{hrs}$ to maintain higher humidity ( $>90 \%)$ under glass house condition. Inoculated plants were observed regularly for the appearance of the disease symptoms. The un-inoculated plants served as control. The symptoms were recorded 7 days after inoculation.

\section{Results and Discussion}

A survey was conducted during Kharif, 2018 in AICRP trials to assess the incidence of sheath blight in different genotypes of small millets and critically observed for symptoms (Fig. 1) and total of fifty three diseased samples containing sclerotia, from each of its respective host (foxtail millet, finger millet, proso millet, little millet) were collected from the experimental plot of AICRP SMALL MILLET at Ranchi centre.

The isolations were made by placing surface sterilized sclerotia on Petri Figs containing PDA medium and incubated at $27 \pm 1^{0} \mathrm{C}$ for 4 days. The isolated pathogens were purified by Hyphal tip method on potato dextrose media. Similarly, Madhavi et al., (2015) isolated $R$. solani from infecting maize and rice var. purified by single hyphal tip method on potato dextrose agar (PDA) at $4^{0} \mathrm{C}$.

Under microscopic examination, the isolates of fungi showed different shades of brown coloured hypha, right angle branching near the distal septum of the cell (Fig. 1). It also exhibited constriction of the branch and presence of a septum in the branch near the point of origin. Singleton et al., (1992) also reported that $R$. solani was characterized by brown septate hyphae with right-angle branching and a slight constriction in the hyphae prior to branching. Adhipathi et al., (2013) and Lal et al., (2014) observed very pale brown to light yellowish brown colour hyphae which exhibited typical hyphal branching at right angle.

Pathogenicity of all isolates obtained from different small millets was proved on Agar method and Sheath inoculum method and used for further cross inoculation and studies. Similarly, Jia et al., (2013) proved the pathogenicity test of $R$. solani by inoculating $0.5 \mathrm{~cm}$ diameter fungal cultures to the sheath of on one month old susceptible rice variety. Baskar et al., (2018), assessed the pathogenicity of $R$. solani by inoculating $1 \mathrm{~g}$ mycelial suspension of pathogen on one month old seedling of rice. Divyaet al., (2018) proved pathogenicity of $R$. solani on healthy trifoliates of groundnut, soybean, moongbean and leaf of maize and rice by keeping in big size desiccators and inoculating the mycelial disc of test fungus and sealing with the help of grease.

\section{Cross inoculation studies}

Cross inoculation studies depicted in table 1 and figures 3, 4, $5 \& 6$ revealed that most of the isolates of $R$. solani were cross infective and exhibited varied levels of pathogenicity at10 days after inoculation. All the proso millet isolates were cross inoculated on 
foxtail millet host. Among all 53 isolates, thirteen isolates were pathogenic to all hosts and found to be most virulent isolates, twelve isolates were pathogenic on three hosts and categorized as virulent isolate, eighteen isolates were pathogenic on two hosts and grouped into moderately virulent isolates and rest isolates were pathogenic only in one host and grouped under a virulent isolates. Similarly, Wang et al., (2015) isolated twenty $R$. solani strains from rice, maize and wheat plants and tested their cross-pathogenicity by artificial inoculation. Each isolate of $R$. solani showed stronger virulence on the original host, while weaker virulence on other hosts. Singh et al., (2018) also conducted Cross infectivity and virulence test by inoculating $R$. solaniof rice and maize on their respect host and resulted that the $R$. solani of maize was more aggressive and virulent than $R$. solani of rice.

Table.1 Cross inoculation studies among the isolates of $R$. solani

\begin{tabular}{|c|c|c|c|c|}
\hline \multirow[t]{2}{*}{ Isolates } & \multicolumn{4}{|c|}{ Cross inoculation } \\
\hline & Foxtail millet & Finger millet & Proso millet & Little millet \\
\hline FOX-01 & + & + & + & + \\
\hline FOX-02 & + & + & - & + \\
\hline FOX-03 & + & - & + & - \\
\hline FOX-04 & + & - & - & + \\
\hline FOX-05 & + & + & - & + \\
\hline FOX-06 & + & - & + & + \\
\hline FOX-07 & + & + & + & - \\
\hline FOX-08 & + & + & + & + \\
\hline FOX-09 & + & + & + & + \\
\hline FOX-10 & + & + & - & - \\
\hline FOX-11 & + & - & - & + \\
\hline FOX-12 & + & - & + & + \\
\hline FOX-13 & + & + & + & + \\
\hline FOX-14 & + & + & + & + \\
\hline FOX-15 & + & + & - & + \\
\hline FOX-16 & + & + & + & - \\
\hline FOX-17 & + & + & + & - \\
\hline FOX-18 & + & - & - & + \\
\hline FM-01 & + & + & + & + \\
\hline FM-02 & - & + & - & - \\
\hline FM-03 & + & + & + & + \\
\hline FM-04 & + & + & + & - \\
\hline FM-05 & + & + & - & - \\
\hline FM-06 & - & + & - & + \\
\hline FM-07 & + & + & - & + \\
\hline FM-08 & - & + & - & + \\
\hline FM-09 & - & + & + & - \\
\hline FM-10 & - & + & + & + \\
\hline FM-11 & - & + & - & + \\
\hline FM-12 & - & + & - & - \\
\hline FM-13 & + & + & + & + \\
\hline
\end{tabular}




\begin{tabular}{|c|c|c|c|c|}
\hline PM-01 & + & + & + & + \\
\hline PM-02 & + & + & + & - \\
\hline PM-03 & + & - & + & - \\
\hline PM-04 & + & + & + & - \\
\hline PM-05 & + & - & + & - \\
\hline PM-06 & + & + & + & - \\
\hline PM-07 & + & - & + & - \\
\hline PM-08 & + & + & + & + \\
\hline PM-09 & + & + & + & + \\
\hline PM-10 & + & + & + & + \\
\hline PM-11 & + & - & + & - \\
\hline PM-12 & + & - & + & - \\
\hline LM-01 & + & - & + & + \\
\hline LM-02 & + & + & + & + \\
\hline LM-03 & + & + & - & + \\
\hline LM-04 & - & + & + & + \\
\hline LM-05 & + & + & - & + \\
\hline LM-06 & + & - & - & + \\
\hline LM-07 & - & - & - & + \\
\hline LM-08 & + & + & + & + \\
\hline LM-09 & + & - & - & + \\
\hline LM-10 & - & - & + & + \\
\hline \multicolumn{5}{|l|}{ SE(m) \pm} \\
\hline \multicolumn{5}{|l|}{ CD at $5 \%$} \\
\hline CV \% & & & & \\
\hline
\end{tabular}

$*+:$ Cross infective

$*-$ : Non cross infective

Table.2 Host range studies of isolates of $R$. solani on different hosts

\begin{tabular}{|l|c|c|c|c|c|}
\hline \multicolumn{1}{|c|}{ Isolates } & Rice & Sorghum & Soybean & Groundnut & Bajra \\
\hline F(FOX) & - & - & + & - & + \\
\hline M(FOX) & + & + & - & - & + \\
\hline S(FOX) & + & + & + & - & + \\
\hline F(FM) & + & + & + & - & + \\
\hline M(FM) & + & + & + & - & - \\
\hline S(FM) & + & + & + & + & + \\
\hline F(PM) & + & - & + & - & - \\
\hline M(PM) & + & + & + & - & + \\
\hline S(PM) & - & - & - & - & - \\
\hline F(LM) & - & + & + & - & + \\
\hline M(LM) & + & + & - & - & + \\
\hline S(LM) & + & + & + & + & + \\
\hline
\end{tabular}

$*+:$ Cross infective

$*_{-}$: Non cross infective 


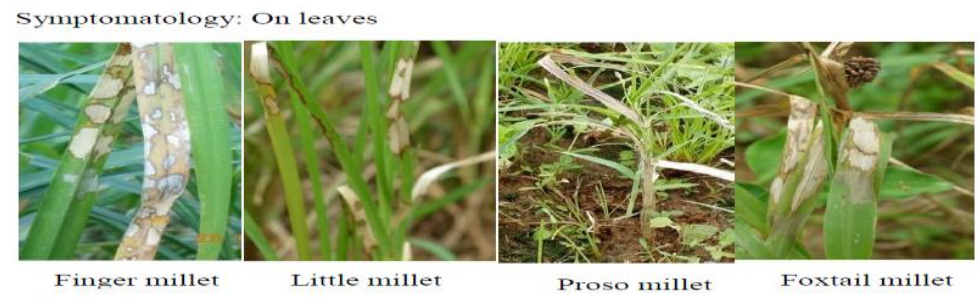

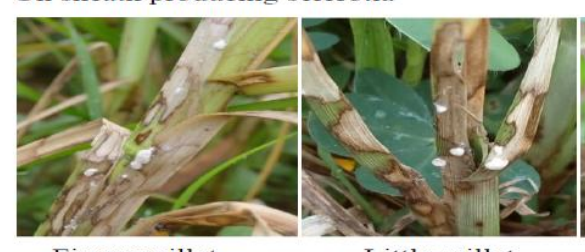

Finger millet
Little millet

Identification of pathogen

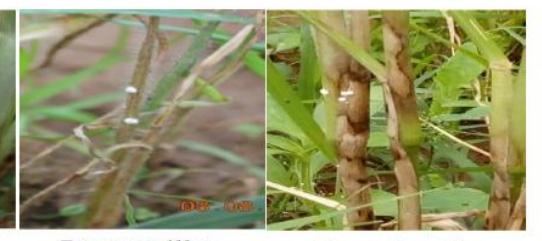

Proso millet

Foxtail millet
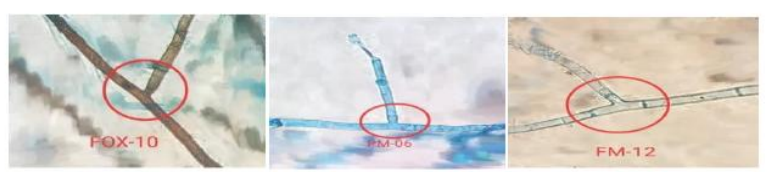

Presence of septa

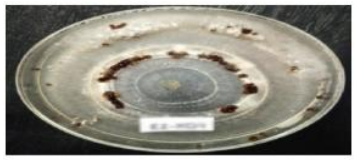

Formation of sclerotia

Fig 1: Symptomatology on leaves of different millets and identification characters of pathogen

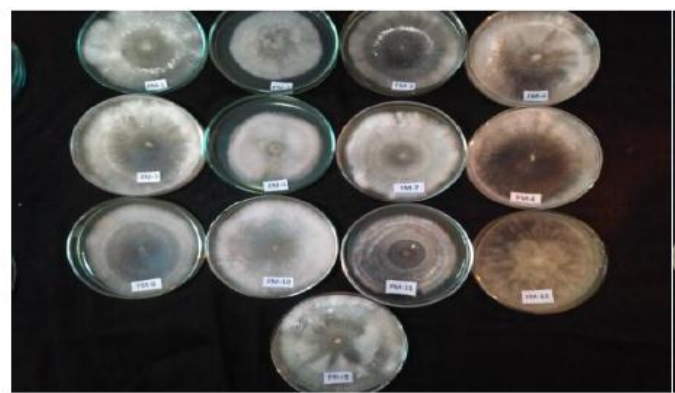

Finger millet

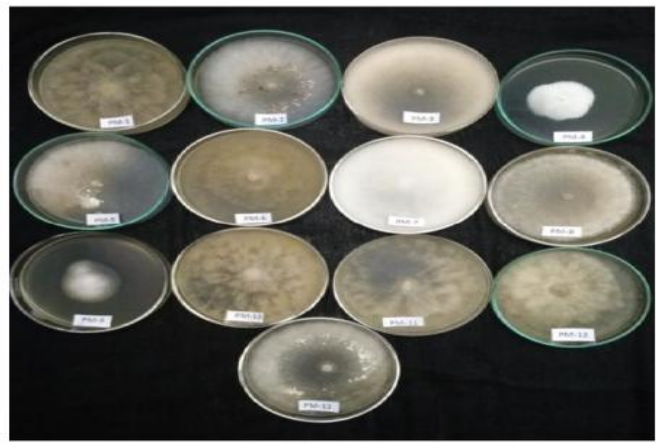

Prosomillet

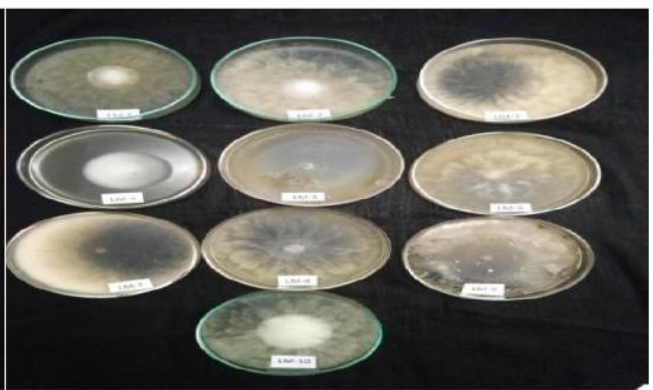

Little millet

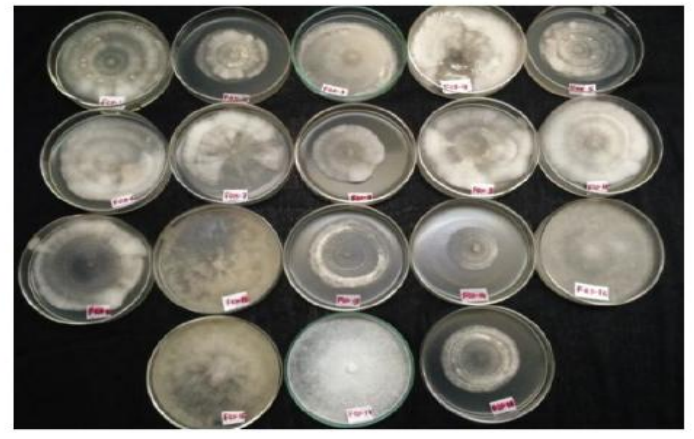

Foxtail millet

Fig 2: Isolation of R.solani Kuhn collected from different Small millets 

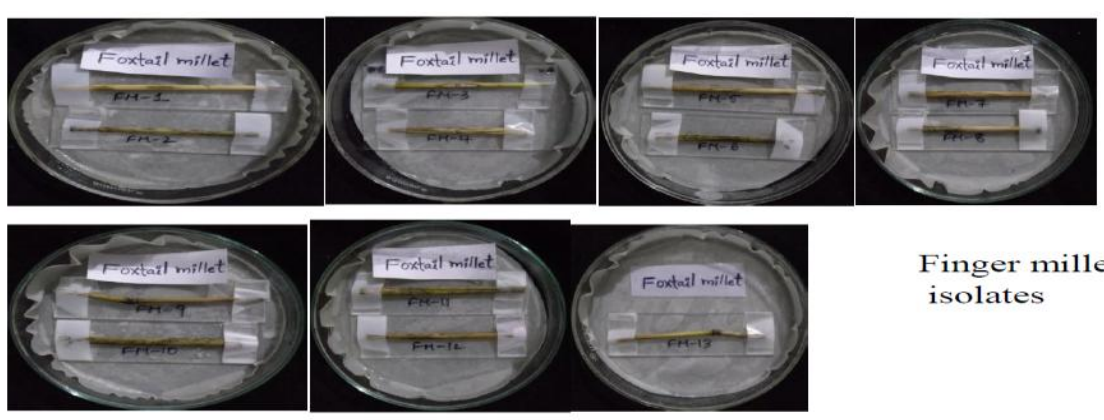

Finger millet isolates
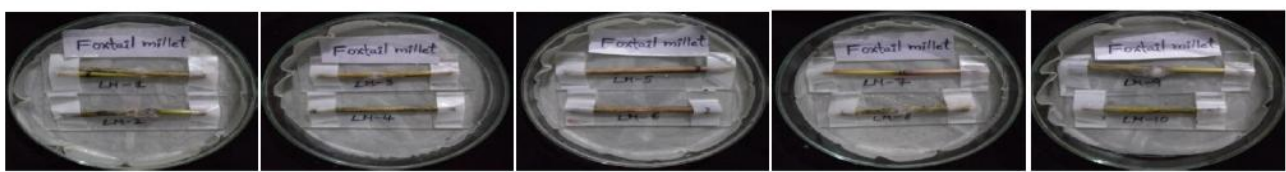

Little millet isolates
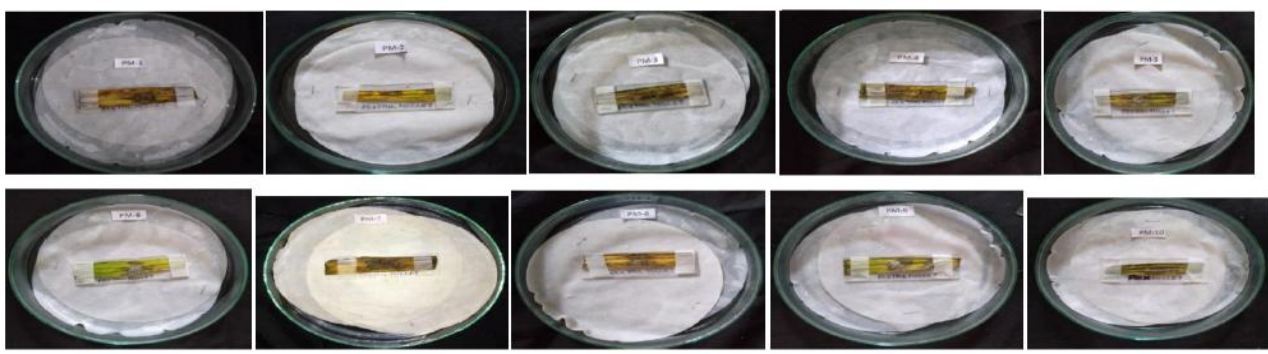

Proso millet isolates

Fig 3: Cross mocuration stuares on foxta11 millet
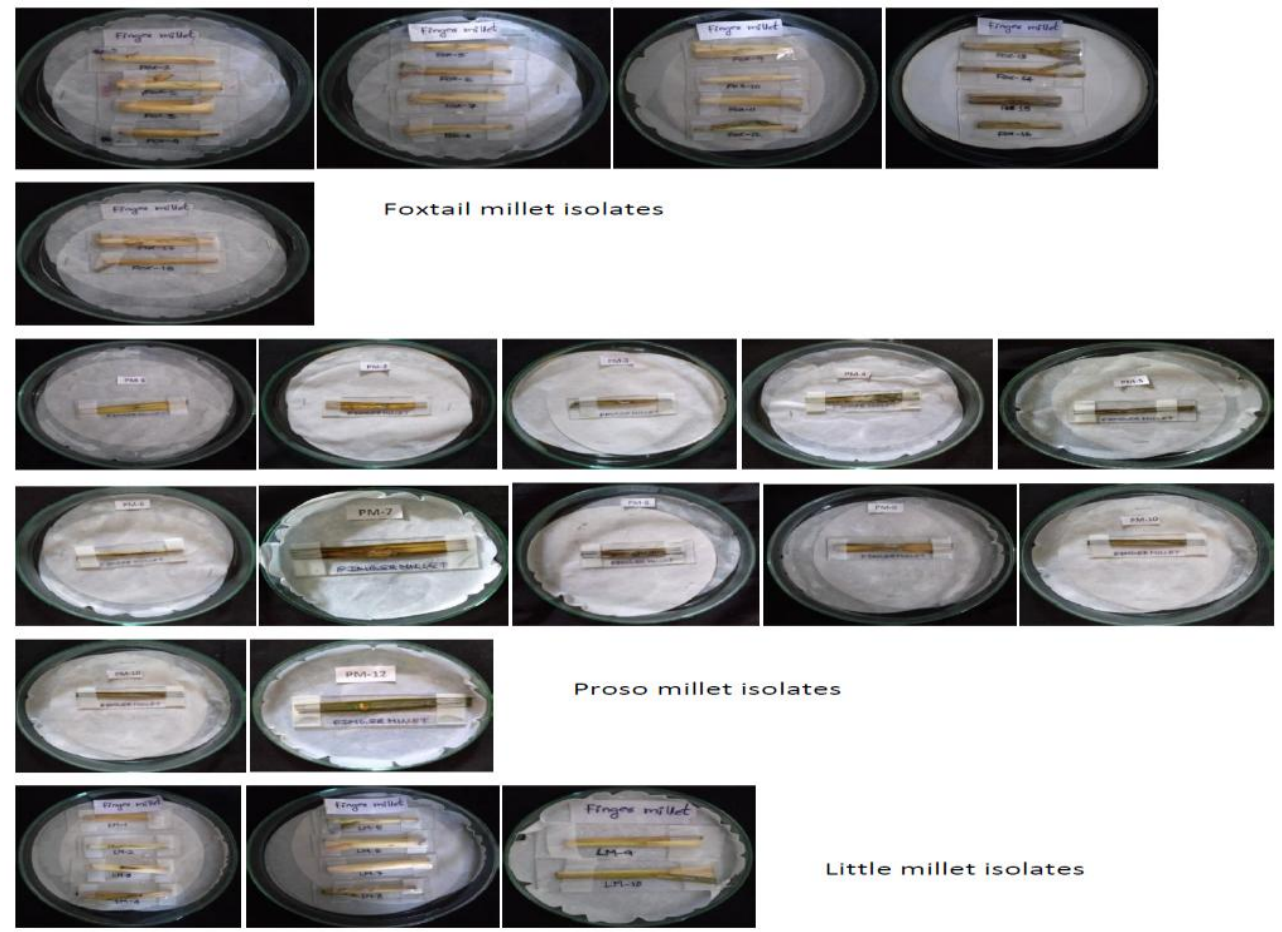

Proso millet isolates

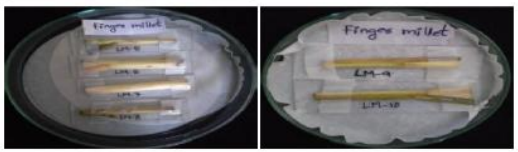

Little millet isolates

Fig 4: Cross Inoculation studies on Finger millet 

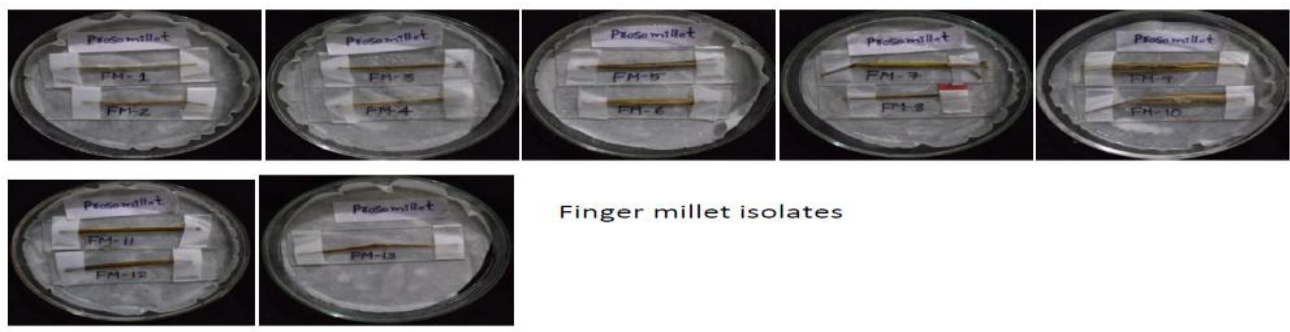

Finger millet isolates
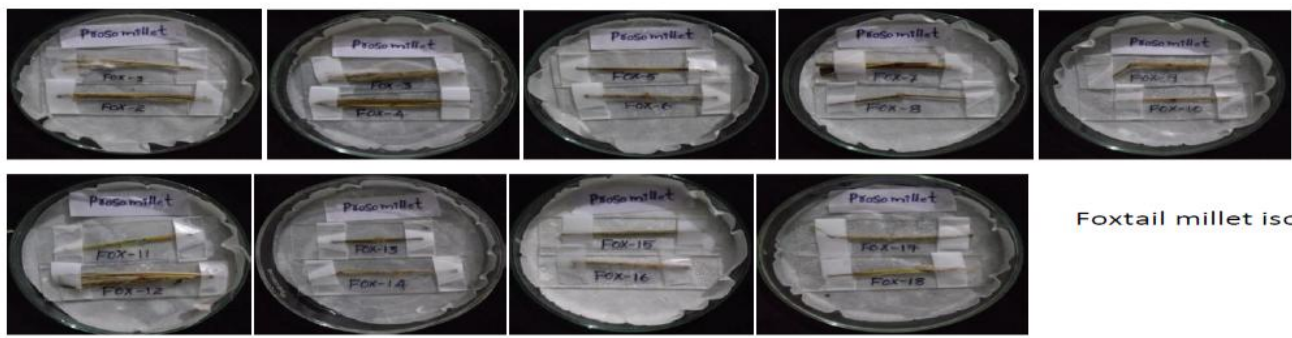

Foxtail millet isolates
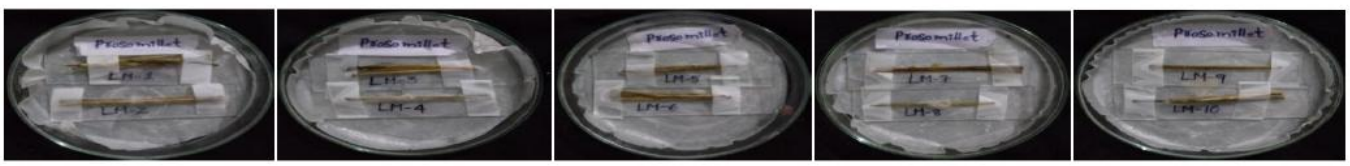

Little millet isolates

Fig 5: Cross Inoculation studies on Proso millet
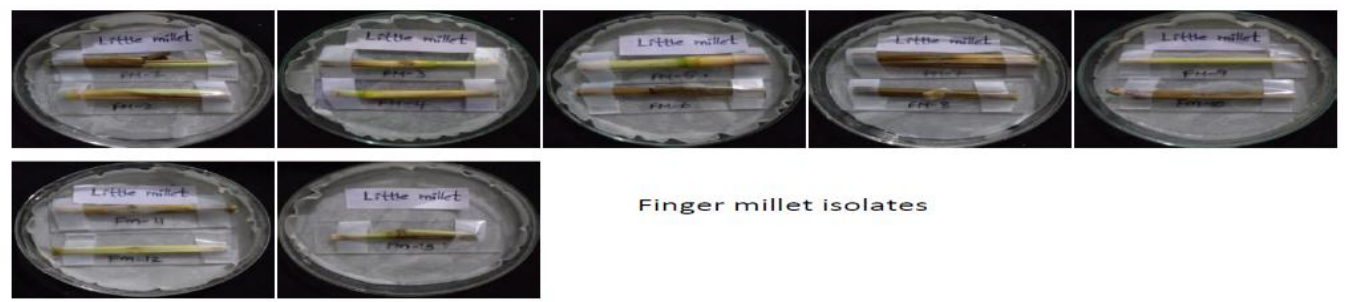

Finger millet isolates
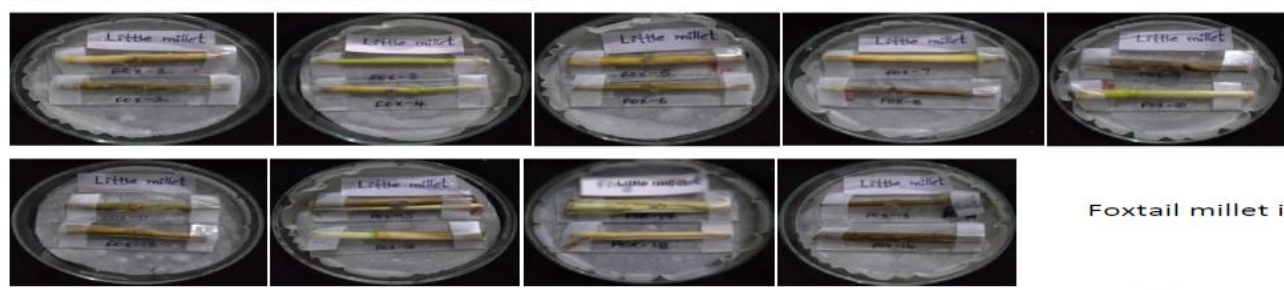

Foxtail millet isolates
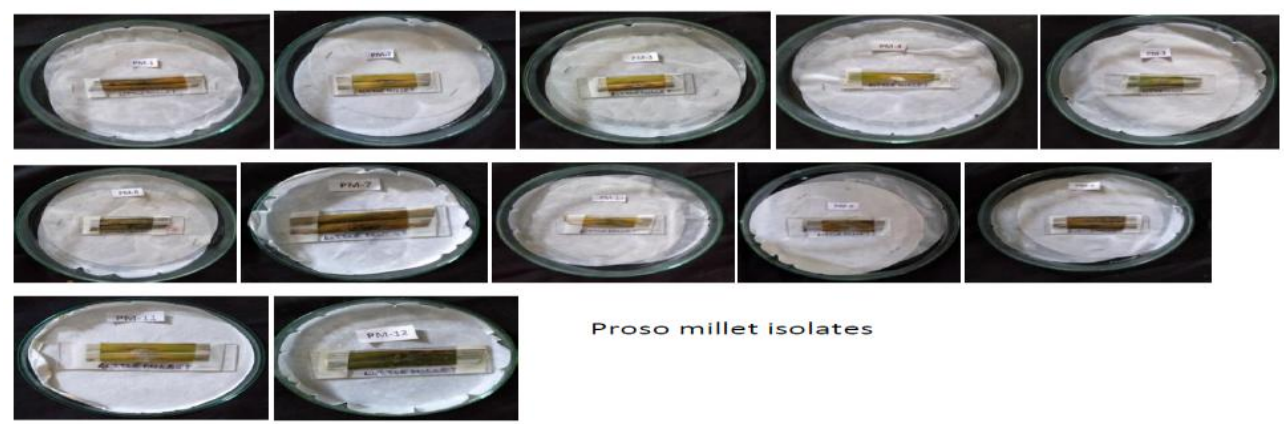

Proso millet isolates

Fig 6: Cross Inoculation studies on Little millet 


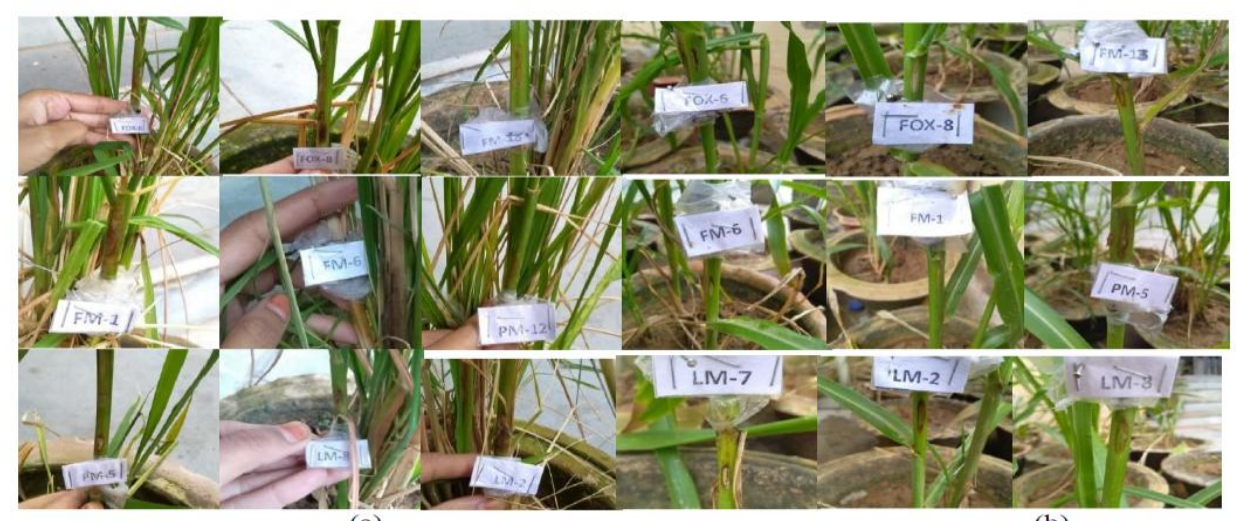

(a)

(b)

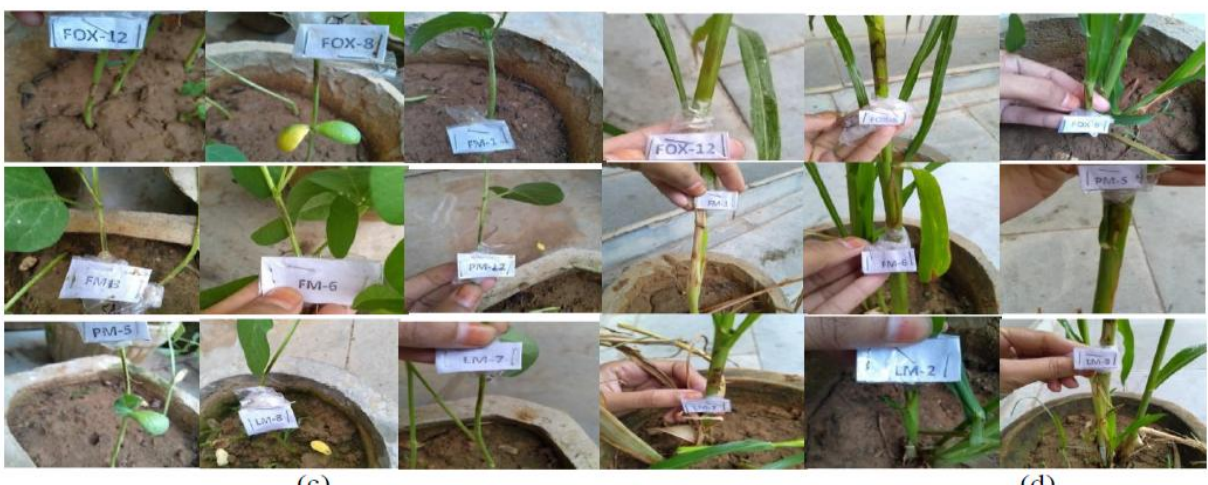

(c)

(d)

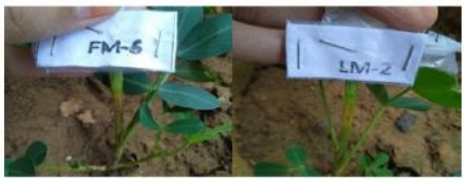

Fig 7: Host range studies in (a) rice (b) sorghum (c) soybean (d) bajra (e) groundnut

\section{Host range studies}

Out of 53 isolates, 12 isolates were selected on the basis of growth rate (Slow, Medium and Fast) and used in host range studies and results depicted in table 2 and fig. 7. Those isolates are $\mathrm{S}(\mathrm{FOX}), \mathrm{M}(\mathrm{FOX}), \mathrm{F}(\mathrm{FOX})$, $\mathrm{S}(\mathrm{FM}), \quad \mathrm{M}(\mathrm{FM}), \quad \mathrm{F}(\mathrm{FM}), \quad \mathrm{S}(\mathrm{PM}), \quad \mathrm{M}(\mathrm{PM})$, $\mathrm{F}(\mathrm{PM}), \mathrm{S}(\mathrm{LM}), \mathrm{M}(\mathrm{LM}), \mathrm{F}(\mathrm{LM})$.

Under present investigation, Host range studies unveiled that all isolates successfully infected rice, sorghum, soybean, bajra except groundnut but their virulences on different crops were quite different. It was observed that slow growing isolates of foxtail millet, finger millet and little millet were more aggressive than medium and fast growing isolates and produced typical symptom on the inoculated host plant. With respect to the susceptibility of the host, they can be categorized into 2 groups. Rice, soybean, bajra, sorghum were found to be highly susceptible and groundnut is moderately susceptible. Lakshmanan and Nair (1985) also reported significant variation while conducting comparative studies of four isolates of $R$. solani (rice, cowpea, jack and cotton) into 14 plant species and found that rice isolates are pathogenic to all 14 plant species whereas other isolates differed in their pathogenicity. In order to find out the host range of $R$. solani (RS-1) isolate, Nagaraj et $a l$. , (2017) found that the pathogen (R. solani) 
successfully infected almost all the species belonging to five families except one weed which belonged to family Fabaceae.

It is concluded that most of the isolates of $R$. solani were cross infective with each other and all the proso millet isolates were more virulent on foxtail millet host. In Host range studies, all isolates successfully infect Rice, sorghum, soybean, bajra except groundnut but their virulences on different crops were quite different. It was observed that slow growing isolates of foxtail millet, finger millet and little millet were more aggressive than medium and fast growing isolates. This indicated that these host plants served as collateral hosts and helped in the spread of the disease in next season. These studies proved that there is a significant amount variation among the isolates with wide host range and cross infective nature.

\section{References}

Adhipathi, P., Singh, V. and Meena, S. C. (2013). Virulence diversity of Rhizoctonia solani causing sheath blight disease in rice and its host pathogen interaction. The Bioscan, 8: 949-952.

Baskar, S., Bharathi, M., Brintha, T., Deepika, S., Vignesh, S. and Raj, T.S. (2018). Evaluation of pathogenicity and methods of inoculation of Rhizoctonia solani Kuhn. Int. J. Inno. Agril. Sci. 2: 94-99.

Dath, P. A. (1985). A better criterion in rating the reaction of rice cultivars against sheath blight. IndianPhytopath. 38: 678-682.

Divya, R., Dantre, R. K. and Kotasthane, A. S. (2018). Studies on variability of Rhizoctonia solani isolated from different hosts and its virulence on rice crop. Int. J. Chem. Stud. 6: 1798-1803.

Dubey, S. C. (1995). Banded blight of finger millet caused by Thanatephorus cucumeris. Indian J. Mycol. Pl. Pathol. 25: 315-316.

Hyakumachi, M., Mushika, T. Y., Ogosi, Y., Toda, T., Kageyama, K. and Tsuge, T. (1988). Characterization of new cultural type of $R$. solani AG-2-2 isolated from warm season turf grass and its genetic differentiation from other cultural type. Plant Pathol. 47: 19.

Jia, Y., Liu, G., Park, D. S. and Yang, Y. (2013). Inoculation and scoring methods for rice sheath blight disease. Methods in Molecular Biology, 956: 257-268.

Lakshmanan, P. and Nair, M. C. (1985). Comparative studies on four isolates of Rhizoctonia solani. Madras Agric. J.72: 653-655.

Lal, M., Singh, V., Kandhari, J., Sharma, P., Kumar, V. and Murti, S. (2014). Diversity analysis of $R$. solani causing sheath blight of rice in India. African $J$. Biotec. 13: 4595- 4605.

Madhavi, M., Narayan Reddy, P., Ranga Reddy, R. and Sokka Reddy, S. (2015). Morphological and Molecular Variability of Rhizoctonia solani Isolates Causing Banded Leaf and Sheath Blight in Maize. Int. J. Bioresource Stress Management, 6: 375385 .

Nagaraj, B. T., Gururaj, S., Pramesh, D., Naik, M. K. and Patil, M. B. (2017). Host Range Studies of Rice Sheath Blight Fungus Rhizoctonia solani (Kuhn). Int.J.Curr.Microbiol.App.Sci. 6: 3856-3864.

Patro, T. S. S. K, Meena, A., Divya, M. and Anuradha, N. (2018). Ecofriendly management of Rhizoctonia solani Kuhn Inciting banded blight using biological control agents in proso millet. J. Pharmacogn Phytochem.7: 2660-2663. 
Ploetz, R. C, Mitchell, D. and Gallaher, R. N. (1985). Characterization \& pathogenicity of Rhizoctoniaspecies from a reduced tillage experiment multicropped to Rye \& soybean in Florida. Phytopathology, 75(7): 833837.

Shailbala and Tripathi, H. S. (2007). Current status of research on web blight disease of urd bean. Agric. Rev. 28:1-9.

Singh, O., Vishwanath., Rana., M. and Erayya. (2018). Cross Infectivity and Virulence of Rhizoctonia solani in Rice and Maize and Its Management -
First Report. Int. J. Pure App. Biosci.6: 465-470.

Singleton, L. L., Mihail, J. D. and Rush, C. M. (1992). Methods for research on soil-borne phytopathogenic fungi. St Paul, MN, USA, American Phytopathol. Soc. Press. pp. 264.

Wang, C. J. Z., He, X. X., Yang, M. and Zhou, E. X. (2015). Crosspathogenicity of Rhizoctonia spp. from rice, maize and wheat on these three crops. J. South China Agril University, 36: $82-86$.

\section{How to cite this article:}

Varala Krishnaveni, Savita Ekka, H. C. Lal and Kudada, N. 2020. Cross Inoculation and Host Range Studies of Rhizoctonia solani Kuhn Infecting Small Millets. Int.J.Curr.Microbiol.App.Sci. 9(11): 1458-1468. doi: https://doi.org/10.20546/ijcmas.2020.911.172 